\title{
Handling Discourse: Gestures, Reference Tracking, and Communication Strategies in Early L2
}

\author{
Marianne Gullberg \\ Max Planck Institute for Psycholinguistics
}

\begin{abstract}
The production of cohesive discourse, especially maintained reference, poses problems for early second language (L2) speakers. This paper considers a communicative account of overexplicit L2 discourse by focusing on the interdependence between spoken and gestural cohesion, the latter being expressed by anchoring of referents in gesture space. Specifically, this study investigates whether overexplicit maintained reference in speech (lexical noun phrases [NPs]) and gesture (anaphoric gestures) constitutes an interactional communication strategy. We examine L2 speech and gestures of 16 Dutch learners of French retelling stories to addressees under two visibility conditions. The results indicate that the overexplicit properties of L2 speech are not motivated by interactional strategic concerns. The results for anaphoric gestures are more complex. Although their presence is not interactionally
\end{abstract}

I gratefully acknowledge financial support from the Max Planck Institute for Psycholinguistics. I thank Alissa Melinger, Leah Roberts, Mandana Seyfeddinipur, and the anonymous reviewers for their valuable input and thoughtful comments. I am also grateful to Alex Dukers, Wilma Jongejan, and Arna van Doorn for assistance in data collection, coding, and establishing reliability. Portions of these data were presented at the European Second Language Association Conference (Eurosla), September, 2002, Basel, Switzerland.

Correspondence concerning this article should be addressed to Marianne Gullberg, Max Planck Institute for Psycholinguistics, P. O. Box 310, NL-6500 AH Nijmegen, The Netherlands. Internet: marianne.gullberg@mpi.nl 
motivated, their spatial articulation is. A learner- and processing-oriented account for both speech and gesture is discussed.

For discourse to be comprehensible and cohesive, you have to know who does what to whom when and where. Information about entities (people and objects), time, space, and actions has to be carefully tracked and managed from one utterance to the next. This is achieved through a process known as anaphoric linking or reference tracking, which allows anaphora resolution (Garrod, 2001). There is a growing body of literature showing that the acquisition of targetlike reference tracking is difficult in a second language (L2) in all domains. When referring to person, for instance, learners of many first languages (L1s) and L2s at an early stage of proficiency produce a similar pattern of reference tracking. In particular, maintained reference causes problems and it is characterized by coreferentially overexplicit speech. Learners consistently overuse lexical nominal expressions in an immediately maintained context and use very few pronouns and zero anaphora (e.g., Carroll, Murcia-Serra, Watorek, \& Bendiscoli, 2000; Extra, Strömqvist, \& Broeder, 1988; Givón, 1984; Hendriks, 2003; Prodeau, 1998). A typical sequence is found in (1).

(1) la dame $e^{\mathrm{i}}$ a eh donnE pour eh la dame $\mathrm{e}^{\mathrm{j}}$ et ehm la dame $\mathrm{e}^{\mathrm{j}}$ allE pour une autre dame $\mathrm{e}^{\mathrm{k}}$ "the lady ${ }^{\mathrm{i}}$ has uh given to uh the lady ${ }^{\mathrm{j}}$ and uhm the lady $\mathrm{j}^{\mathrm{j}}$ go one other lady"

All referential expressions in this passage are marked by a lexical noun phrase (NP); there are no pronouns or zero anaphora. In L1 production, the immediately maintained referent, la dame $e^{j}$, would typically have been demoted to a pronoun or even a zero anaphor in the absence of a pragmatic reason for keeping the full lexical NP (e.g., Fox, 1987; Givón, 1984). In L2 production, however, no such demotion or pragmatic differentiation is found. Instead, there is a persistent use of lexical NPs. This pattern seems to hold for many learners, regardless of the L1 and L2 involved (but see Hendriks, 2003), suggesting that it constitutes a so-called learnervariety feature (Klein \& Perdue, 1997; Perdue, 1996). 
Why should reference tracking be difficult in L2? The general principles of reference tracking whereby new and maintained information is distinguished by overt marking are assumed to be known from the L1. ${ }^{1}$ Learners would, therefore, be expected to transfer the principles from their L1 and apply them in the L2 even if they have other surface means for doing so than native speakers have. It is somewhat perplexing that learners should prefer something to nothing-full lexical NPs over Ø. Various explanations have been proposed to account for coreferentially overexplicit reference tracking in L2. One suggestion is that the pattern is a natural reflection of the fact that lexical means are acquired before grammatical ones such as pronouns (Hendriks, 2003). A communicative account has been suggested to the effect that learners deliberately avoid errorprone pronominal forms that encode several grammatical distinctions simultaneously: gender, number, and case. Instead, learners favor full lexical NPs in a desire for hyperclarity (Williams, 1988). Finally, a recent, process-oriented approach suggests that learners avoid pronouns because their deployment requires planning beyond the level of the single clause, and at two levels simultaneously (Carroll \& Lambert, 2003; Carroll et al., 2000; Prodeau, 1998). At any point in time, the choice of a particular form (indefinite or definite lexical NPs, pronouns, or zero anaphora) is determined by the interaction between grammar at a local level of the utterance and information structure at the global level of the discourse. Local grammatical decisions concern gender, number, and case. Global decisions relate to information structure, such as whether the referent is new or has been mentioned before, how long ago, and so forth. Such a double planning load is too heavy for learners at this stage. By opting for lexical NPs throughout, learners can plan at one level only and thus alleviate the processing load.

This study will consider an alternative option by taking the gestures that accompany referential expressions for person into account. The starting point is the observation that reference tracking is a bimodal phenomenon and that gestural reference 
tracking differs systematically in L1 and L2 in ways similar to spoken reference tracking. Maintained referents in L2 speech are nominally overmarked, as we have seen. These same maintained referents are also overmarked in gesture in the sense that they are accompanied by (anaphoric) gestures at every mention (Gullberg, 1998, 2003). Taking the cohesive properties of each modality into account, this study investigates whether overexplicit maintained reference in L2 speech and gesture constitutes an interactional communication strategy.

\section{Reference Tracking and Gestures}

\section{Gestural Cohesion in L1}

Gestures, defined as the (mainly manual) movements speakers perform unwittingly while they speak (cf. Kendon, 1986, 2004; McNeill, 1992), are closely and systematically related to language and speech. Gestures are semantically coexpressive with speech, such that they often convey meaning also present in speech either iconically, or by way of spatial contiguity, or indexicality. Gesture and speech are also temporally coexpressive such that the gesture occurs at the same time as the speech unit with which it is semantically coexpressive. Gestures defined in this way have been shown to reflect both lexical and discursive linguistic structures (e.g., Duncan, 1994; Kita \& Özyürek, 2003; McNeill, 1992).

Gestures and space have rich cohesive affordances. The mechanism of gestural cohesion rests on the continued or recurring gestural patterns-handedness, hand configuration, or specific spatial area-associated with consistent visuospatial imagery or referential content over a stretch of discourse. McNeill called such recurring associations "catchments" (McNeill, 2000). The association can be accomplished through iconicity or through indexicality. A number of studies have shown that reference tracking in L1 narratives is characterized 
by systematic and repeated associations between specific gestural behavior and referential expressions in speech (Levy \& McNeill, 1992; Marslen-Wilson, Levy, \& Komisarjevsky Tyler, 1982; McNeill \& Levy, 1993). When a referent is first introduced, it is often associated with a particular point in space, a locus, by way of a localizing gesture, typically a pointing gesture or an iconic gesture that is "deictically inflected" (Kendon \& Versante, 2003). The locus is arbitrary and abstract and bears no relationship to actual space. However, once established, it is often maintained throughout discourse such that speakers refer back to the locus when they reintroduce the referent associated with it. As referents and loci multiply, speakers charge concrete gesture space with referential meaning and turn it into a map of discourse. This map allows the establishment of explicit, visual coreference. The mechanism of gestural cohesion and its effects are reminiscent of grammatical procedures in Sign Language (e.g., EngbergPedersen, 1993; Liddell, 2003).

Example (2) is an extract of a narrative in native Swedish. Two new referents are introduced: en tjej "a girl" and föreståndarn "the manager."

(2) så visar hon de eh till eh då en [tjej] $]^{\mathrm{i}} \mathrm{i}$ disken

som $^{\mathrm{i}}$ tar detta då

å $\emptyset^{i}$ tycker att det ser mycke mystiskt ut

varefter hon tar de till typ [föreståndarn] ${ }^{\mathrm{j}}$

som $^{\mathrm{j}}$ också tycker de ser mycke mystiskt ut

"so she shows it uh to uh then to a [girl] ${ }^{\mathrm{i}}$ at the counter

who ${ }^{\mathrm{i}}$ takes this then

and $\emptyset^{\mathrm{i}}$ thinks that it looks very mysterious

whereupon she takes it to the like [manager $]^{j}$

who ${ }^{j}$ also thinks it looks very mysterious" 
In speech, the alternation between lexical NPs for new referents (tjej, föreståndarn) and pronouns and zero anaphora for maintained referents is evident. In gesture, the speaker anchors the two new referents in space with gestures, indicated in the transcription by square brackets. When reference is maintained-marked by pronouns or zeros in speech-there are no gestures. Notice that although the localizing gestures are spatial-as all gestures have to be-they are not associated with locative or spatial expressions in speech. They coincide precisely (or down to a level of $40 \mathrm{~ms}$, which is the duration of a video frame) with the referential expressions.

\section{Gestural Cohesion in L2}

In a study of early Swedish learners of French and French learners of Swedish, Gullberg $(1998,2003)$ showed that gestural reference tracking in L2 differs systematically from gestural reference tracking in L1. Specifically, maintained reference in L2 gesture differs from maintained reference in L1 gesture in the same way as L2 speech differs from L1 speech: It is overexplicit. As mentioned earlier, in L1 production referents are spatially anchored in gesture space at their introduction and unmarked when maintained. In L2 production, in contrast, referents are gesturally anchored at their introduction and when maintained by lexical NPs. Learners localize a new referent in space with a gesture at its introduction. At the immediately following mention, they produce another, anaphoric gesture indicating the same locus in space.

(3) la [femme $]^{\mathrm{i}}$ qui est [dans la réception]

et [la femme $]^{\mathrm{i}}$ ne comprend pas

et [la femme] $]^{i}$ [dans le réception] euh donnE la script euh de [le supervisée ${ }^{j}$

[de la pharmacie]

"the [woman] $]^{\mathrm{i}}$ who is [in the reception] 
and [the woman] $]^{\mathrm{i}}$ doesn't understand

and [the woman] ${ }^{\mathrm{i}}$ [in the reception] uh give the script uh to [the supervisor] ${ }^{\mathrm{j}}$

[of the pharmacy]"

In (3) the same learner retells the same story segment as before, but this time in L2 French. Speech is characterized by lexical NPs and an absence of pronouns. In particular, maintained reference, indicated by superscript in the example, is marked by lexical NPs. In gesture, the new referents are localized in space when introduced: la femme "the woman" and le supervise "the supervisor." These expressions are further modified by locative expressions, "in the reception" and "of the pharmacy," also marked in gesture. When they are maintained, the speaker again immediately indicates the associated loci with anaphoric gestures. Maintained reference is thus overexplicit in both modalities: lexical NPs in speech and anaphoric gestures. Strikingly, the two modalities are influenced by grammatical development in parallel ways. When learners begin to use pronouns for maintained reference (even if formally erroneous), the number of anaphoric gestures drops significantly.

\section{Is Overexplicitness an Interactional Communication Strategy?}

Previous accounts of the overexplicit character of early learner discourse have focused on speech alone. The existence of a gestural parallel to the learner variety of reference tracking raises the question of what role these gestures play in L2 production and, specifically, whether they have any bearing on the overexplicit nature of L2 speech.

Nominal maintained reference is not optimal for successful reference tracking or anaphora resolution because the distinction between new and old information is blurred. The standard interpretation of a lexical NP is that it refers to a new entity or introduces a thematic shift (cf. Fox, 1987; Vonk, Hustinx, \& Simons, 1992). By using lexical NPs for maintained reference, 
learners violate a host of rules for anaphora resolution: various givenness hierarchies and accessibility scales (Ariel, 1990; Chafe, 1994; Givón, 1984), the Gricean quantity principle (Grice, 1975), conversational implicatures (Levinson, 2000), relevance (Sperber \& Wilson, 1986), principles of recipient design (Sacks \& Schegloff, 1979), and even the Zipfian principle of least effort (Zipf, 1949). There is both interactional (Gullberg, 1998) and experimental evidence (e.g., Cloitre \& Bever, 1988; Garrod, Freudenthal, \& Boyle, 1994; Vonk et al., 1992) to suggest that such overexplicitness causes comprehension difficulties for listeners. Instead of being hyperclear, as proposed by Williams (1988), learners' speech is ambiguous and noncohesive.

Although learners' speech is ambiguous, their gestures are not. The association between a unique referent and a locus in space is clear and unequivocal. Spatial anchoring and the repeated indication of a locus allow visual and explicit coreference to be established even in the absence of clear-cut distinctions in speech (cf. Levy \& Fowler, 2000). The physical and spatial properties of gestures make them ideally suited for disambiguation. Learners could exploit them to identify or disambiguate in gesture what they cannot distinguish in speech: that which is new from that which is maintained. It therefore seems plausible that learners use gestures as an interactional communication strategy to overcome problems with overexplicit and, consequently, noncohesive speech.

Gestures are good candidates for strategies. Previous work has shown that gestures are used strategically in L2 production in several ways (Gullberg, 1998). They are exploited to solve lexical problems, typically in conjunction with speech to solicit lexical help from the native interlocutor. Gestures are also used metacommunicatively to manage problematic interaction by flagging ongoing word search, floor keeping, and so forth. Most interestingly, however, gestures play an important role in overcoming grammatical problems. Difficulties related to tense and aspect are solved by using gestures to metaphorically represent 
time as space (Gullberg, 1999). Given this versatility, it seems plausible that gestures should also be exploited to disambiguate discourse. Recall that gestures in L2 accompany precisely those referential expressions in speech that are ambiguous (i.e., the lexical NPs that mark maintained reference). Moreover, these gestures disappear when learners develop pronouns and the grammatical means to construct cohesive discourse. The more cohesive the discourse, the fewer anaphoric gestures we find. The gestural reflection of the learner variety would thus allow learners to solve problems of ambiguity in speech by providing spatial scaffolding for cohesion. It is worth pointing out that gestural reference tracking is not linked to lexical difficulties. Learners who have lexical problems but use pronouns do not mark pronominally encoded referents with gestures. Conversely, learners with no evident lexical difficulties but who do not use pronouns do mark maintained referents expressed by lexical NPs with anaphoric gestures. Therefore, the phenomenon at hand is not an example of a gestural lexical compensatory strategy (cf. Gullberg, 1998).

As in traditional research on communication strategies, the issue of identifying strategic behavior is crucial and different frameworks have offered different criteria (for overviews, see Dörnyei \& Scott, 1997; Kasper \& Kellerman, 1997; Yule \& Tarone, 1997). Interactional frameworks have typically identified strategies by their surface forms in the output (e.g., Tarone, 1980). Psycholinguistic and cognitive approaches, attempting to deal with underlying speaker-internal processes, have relied on clusters of behavioral cues (e.g., Bialystok, 1990, 1994; Faerch \& Kasper, 1983a, 1983b, 1984; Kellerman \& Bialystok, 1997; Poulisse, 1990, 1994). At first glance, gestures would seem to constitute a prototypical interactive type of strategy, given their spatial and physical nature. This seems particularly likely given the considerable evidence showing that addressees make use of and attend to gestural information in interaction. Addressees have been shown to pick up information only present in gestures and integrate it into their 
meaning representations (e.g., Beattie \& Shovelton, 1999; Berger \& Popelka, 1971; Cassell, McNeill, \& McCullough, 1999; Church \& Goldin-Meadow, 1986; Graham \& Argyle, 1975; Kelly, Barr, Breckinridge Church, \& Lynch, 1999; Langton, O’Malley, \& Bruce, 1996; Riseborough, 1981). Specifically, when exposed to cohesive or indexical gestures that are inconsistent or in conflict with speech, addressees experience problems reconstructing narratives (Cassell et al., 1999). Moreover, when native addressees in native/nonnative interaction try to disambiguate reference, they often use the loci established by the learners, as in (4).

(4) (learner: la femme donnE la script de le supervisé)

NS: et à ce moment-là [tout] le monde comprend

"and at that moment [every]body understands"

The native speaker (NS) clearly indicates the loci previously established by the learner as associated with the referents included in "everybody." This spatial information has only been available in the learner's gestures. Despite the absence of overt attention to gestures during discourse, the addressee has, nevertheless, covertly attended to and integrated the gestural information.

Thus, there is plenty of evidence that addressees attend to gestures. Establishing whether speakers' use of gesture is always intended for the addressee is a more difficult issue. Most gestures are typically performed with a high degree of automaticity and little awareness. Speakers often do not remember having performed a specific gesture even when it has been the subject of negotiation. Also, as for other types of communication strategies, learners might perform gestures in contexts of potential ambiguity with little or no awareness, much in the same way as they can circumvent other communicative problems before these become manifest. In contrast to spoken strategies, however, determining what is interactionally intended gestural behavior can be investigated (cf. Holler \& Beattie, 2003; Melinger \& Levelt, 2004). We can examine 
whether anaphoric gestures are part of an interactional, addressee-directed, disambiguating strategy by manipulating visual access between learners and their addressees. Such a design will reveal to what extent learners actually consider their addressees when deploying anaphoric devices in speech and gesture in conjunction.

Previous studies using the visual access paradigm have shown that the absence of visual access between speaker and addressee cause a general reduction in gesture frequency (e.g., Alibali, Heath, \& Myers, 2001; Bavelas, Chovil, Lawrie, \& Wade, 1992; Cohen, 1977; Cohen \& Harrison, 1973). The logic underlying these studies is that gestures that are intended for the addressee will disappear when there is no visual access between speaker and addressee. Conversely, the gestures that remain will mainly play a speaker-internal role. Note that the majority of these studies have been concerned with iconic gestures and lexical content rather than with localizing gestures, grammar, and discourse.

This study will manipulate visible access between interlocutors to examine two related questions: (a) Is the overexplicit nature of maintained reference in L2 speech a communication strategy, dependent on co-occurring disambiguating gestures? (b) Are those learner gestures that accompany overexplicit referential expressions an interactionally motivated communication strategy to disambiguate speech?

First, as indicated earlier, overexplicit maintained reference in L2 leads to noncohesive speech that is difficult to understand for addressees. This is because the distinction between new and old information is blurred when all referents are marked by lexical NPs. A possible answer to the question of why L2 speakers nevertheless produce overexplicit speech is that they might be relying on concomitant gestures to disambiguate speech and provide cohesion. If the overexplicit nature of L2 speech depends on the presence of disambiguating gestures, it is possible that a manipulation of visible access to the gestures will affect learners' speech. If disambiguating gestures cannot be seen by the addressee, L2 speakers might attempt to make 
speech alone more cohesive, which would mean reducing the number of full lexical NPs for maintained reference and increasing the number of pronouns and zero anaphora.

Second, as we have seen, maintained reference is also overexplicit in gesture: Anaphoric gestures occur with expressions of maintained reference in L2 speech at every mention. If these anaphoric gestures are mainly driven by interactional concerns, intended for the addressee to help disambiguate speech, then they should be affected by a manipulation of visibility. If L2 speakers cease to produce anaphoric gestures for maintained reference when these cannot be seen by addressees, this would suggest that the gestures serve mainly an interactional purpose. If, on the other hand, L2 speakers continue to produce them even if the addressee cannot see them, a more speaker-internal motivation for the anaphoric gestures will have to be considered.

The predictions for speech and gesture related to maintained reference in L2 are summarized in (1) and (2) and in Table $1 .^{2}$

1. If overexplicit speech is an interactionally motivated communication strategy and dependent on the copresence of disambiguating anaphoric gestures, then speech should be sensitive to manipulations of visibility such that in the condition with no visibility, -Vis, speech is more cohesive and less explicit, showing an increased use of pronouns and zero anaphora.

Table 1

Predictions for maintained reference in L2 speech and gesture

Maintained

reference Communication strategy $(+\mathrm{Vis} \neq-\mathrm{Vis})$

\begin{tabular}{|c|c|c|c|}
\hline (a) Speech & $\begin{array}{l}+ \text { Vis: full lexical } \\
\text { NPs }\end{array}$ & vs. & $\begin{array}{l}\text {-Vis: few lexical NPs, more } \\
\text { pronouns, } \varnothing\end{array}$ \\
\hline (b) Gesture & $\begin{array}{l}\text { +Vis: anaphoric } \\
\text { gestures }\end{array}$ & vs. & $\begin{array}{l}\text {-Vis: few or no anaphoric } \\
\text { gestures }\end{array}$ \\
\hline
\end{tabular}


2. If anaphoric gestures accompanying expressions of maintained reference are an interactionally motivated communication strategy to disambiguate noncohesive speech, they should be sensitive to manipulations of visibility such that in the condition with no visibility, -Vis, there are fewer or no anaphoric gestures.

Notice that although the bimodal phenomenon is considered to be a composite (cf. Clark, 1996), the relationship between the predictions for speech and gesture is not causal; that is, even if overexplicit speech turns out not to be affected by the visibility manipulation, and therefore not part of an interactional communication strategy, anaphoric gestures could still be part of such a strategy.

\section{Method}

Story retellings were used to elicit spoken discourse and gesture. All participants told stories in L1 and L2 under two visibility conditions counterbalanced for order. Each participant contributed four narratives. Two analyses will be presented in the following: (1) Replication: Speech and gesture performance in L1 and L2 under full visibility will be investigated in order to replicate the findings from Gullberg (2003) in a new language pair. (2) Visibility effects: L2 speech and gesture in two visibility conditions will be analyzed to test whether speech and gesture change depending on visibility (cf. Table 1). Specifically, we will investigate whether L2 speech becomes less nominal and whether anaphoric gestures disappear in the nonvisibility condition.

\section{Participants}

Sixteen Dutch foreign language learners of French (i.e., speakers with Dutch as their first language and French as a foreign language taught at school) participated in this study. They were paid for their participation. At the time of testing, 
they had studied French as a foreign language for a maximum of 4 years and they had never lived in a French-speaking country. In some cases, 3 years had lapsed between their last contact with the language and the time of testing.

Because speakers do not always gesture, the analyses to be presented will be based on different subsets of participants. The replication study is based on data from those eight participants who provided speech and gesture data in both L1 and L2 +Vis. Similarly, the visibility effect analyses will draw on data from those 10 participants who provided speech and gesture data in L2 in both visibility conditions.

\section{Materials and Procedure}

Two printed wordless cartoons were used as stimuli. In both cartoons, a number of referents of the same gender go back and forth between people and locations in order to solve a problem. The narratives thus give rise to the need to refer to and distinguish multiple referents who share certain characteristics in an immediate context.

To ensure gesturing, an interlocutor was present at each retelling (cf. Alibali et al., 2001; Bavelas et al., 1992; Cohen, 1977). Each story was told to a native speaker of the target language (i.e., in the L1 condition to a native speaker of Dutch, and in the L2 condition to a native speaker of French). To further induce gesturing, the confederate native speakers were introduced as naïve participants who were unfamiliar with the stories.

The learner was presented with the first cartoon and given time to memorize it. The confederate interlocutor was then introduced into the room. The learner was instructed to retell the story to the interlocutor such that the interlocutor could retell the story in her/his turn. The confederate was given "fake" instructions to listen carefully and to ask as many questions as necessary in order to understand the story. This arrangement was intended to convince the learner of the need 
for detail and precision in the narrative. It also encouraged interaction. The questions were not scripted. After the first retelling, the confederate was taken to another room where she/he was said to be tested on the story. Meanwhile, the learner participant was presented with the second cartoon and memorized it. A second experimenter arranged the setup to allow for the appropriate visibility condition. A new confederate interlocutor was then introduced into the room, and the learner participant proceeded to retell the new story. This procedure was repeated until each participant had retold four stories.

Instructions were given in the language of the retelling. In the visible condition, the participants were seated face-to-face across a table. The setup was the same in the nonvisible condition, but a screen prevented eye contact and gesture inspection. An example of the setup in the nonvisible condition is presented in Figure 1.

All retellings were videotaped and audio-recorded and written consent was obtained from all participants. A post hoc questionnaire was administered to check that participants did not identify gestures as the target of study.

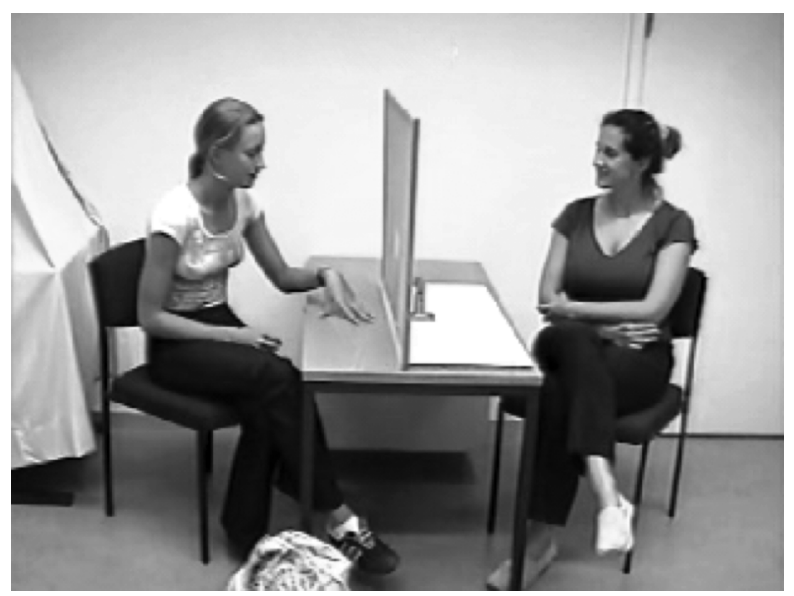

Figure 1. Example of Mediatagger coding from the -Vis condition. 


\section{Coding}

All stories were transcribed verbatim. Although the analyses in this paper focus on maintained reference, all referential expressions in the transcriptions were coded for their discursive status as introduced, maintained, or reintroduced. The definitions of these coding categories are summarized in Table 2. Notice that the definition for maintained reference is very strict for the purposes of this paper. The linguistic form for each referential expression was also coded (viz. lexical NP [NP Lex], pronoun [NP Pron], or zero anaphora [NP $\varnothing])$. A second person coded a subset of the data (25\%). The interrater reliability for the discursive categories was .94 $(N=653)$.

The video recordings were digitized and coded using Mediatagger 3.1 (Brugman \& Kita, 1995), a software for video annotation developed at the Max Planck Institute for Psycholinguistics. An example of the coding is shown in Figure 1. Gestures co-occurring with expressions for person (firstorder referents) were identified. ${ }^{3}$ When gestures and their co-occurring referential expression were repeated as a result of disfluency, the resulting speech-gesture ensemble was considered only once. The set of coded gestures are strokes of localizing gestures and their (poststroke) holds (i.e., instances

Table 2

Speech: Discourse status categories and definitions

\begin{tabular}{ll}
\hline Discourse status & \multicolumn{1}{c}{ Definition } \\
\hline Introduced & $\begin{array}{l}\text { First mention of a referent, independent of clause } \\
\text { position }\end{array}$ \\
Maintained & $\begin{array}{l}\text { A referent having appeared in any position in the } \\
\text { previous clause appearing in the current clause as } \\
\text { sentential subject }\end{array}$ \\
& $\begin{array}{l}\text { A referent appearing subsequent to a clause with a } \\
\text { Reifferent sentential subject }\end{array}$ \\
\hline
\end{tabular}


where the gesture is stopped and held in gesture space (Kendon, 1972; Kita, van Gijn, \& van der Hulst, 1998). The interrater reliability for gesture identification on $25 \%$ of the data was .93 $(N=95)$.

\section{Results}

The Replication Analysis: Maintained Reference in L1 Versus L2 Speech and Gesture Under Full Visibility

This analysis compares speech and gesture production in $\mathrm{L} 1$ and L2 in the + Vis condition. The purpose is to replicate the findings in Gullberg (2003), where maintained reference was found to be overexplicit in both modalities in L2 French and L2 Swedish. In order to establish such a learner variety of maintained reference in this new language pair (DutchFrench), speech and gesture in L1 and L2 under full visibility are analyzed. First, speech is analyzed to determine whether maintained reference in L2 is more likely to be encoded by lexical NPs than by pronouns. Second, gesture is analyzed to ascertain whether (nominal) expressions of maintained reference are more likely to be accompanied by gestures in L2 than in L1.

Examples (5) (L1 production) and (6) (L2 production) illustrate the data.

(5) $[\text { Die andere twee }]^{\mathrm{i}}$ worden allebij heel boos

en $\emptyset^{\mathrm{i}}$ rennen naar de derde $\mathrm{dwerg}^{\mathrm{j}}$ naartoe

en $\operatorname{die}^{\mathrm{j}}$ ziet ineens zo'n driehoek ding

"[the other two $]^{\mathrm{i}}$ are both very angry

and $\emptyset^{\mathrm{i}}$ run to the third dwarf $\mathrm{f}^{\mathrm{j}}$

and he $\mathrm{e}^{\mathrm{j}}$ sees suddenly a sort of triangle thing" 
(6) $[\text { Les deux nains }]^{\mathrm{i}}$ fit pour le [troisième nain $]^{\mathrm{j}}$

$[\text { le troisiéme nain }]^{\mathrm{j}}$ regarde $[\mathrm{lE} \text { deux }]^{\mathrm{i}}$

"[the two dwarfs $]^{\mathrm{i}}$ make to the [third dwarf $]^{\mathrm{j}}$

[the third dwarf] ${ }^{\mathrm{j}}$ looks at [the two $]^{\mathrm{i},}$

Example (5) shows the typical pattern for L1 production. New referents are encoded by full lexical NPs with accompanying gestures: die andere twee "the other two." Maintained referents, indicated by the superscripts in the example, are encoded with pronouns, $\emptyset^{i}, d i e^{j}$ "he," and no gestures. Example (6) illustrates the typical L2 pattern. New referents, les deux nains "the two dwarfs" and le troisième nain "the third dwarf" are encoded by full lexical NPs and accompanied by gestures, as in L1. However, in contrast to L1, an immediately maintained referent, le troisième nain ${ }^{j}$ "the third dwarf," is indicated with a full lexical NP and an anaphoric gesture.

Figure 2 presents the mean proportion of instances of maintained reference encoded as NP Lex, NP Pron, or NP Ø in $\mathrm{L} 1$ and L2. A repeated measures analysis of variance (ANOVA) with encoding category (NP Lex, NP Pron, NP Ø) and language

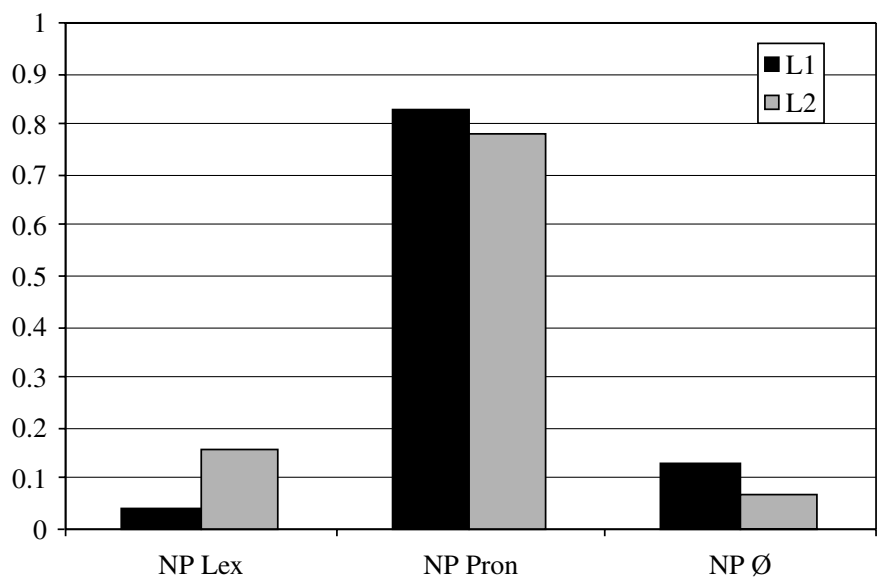

Figure 2. Mean proportion of instances of maintained reference encoded as NP Lex, NP Pron, or NP $\varnothing$ in L1 and L2. 
(L1, L2) as the within-subject factors was run on the mean scores. ${ }^{4}$ The analysis showed a significant main effect of encoding category, $\quad F(2,6)=223.38, \quad p \leq .00, \quad \eta^{2}=.99, \quad$ and a significant interaction of encoding category by language, $F(2,6)=9.48, p \leq .01, \eta^{2}=.76$, suggesting that the participants encoded maintained reference differently in L1 and L2. Paired samples $t$ tests indicated that the maintained category was significantly more likely to be encoded by NP Lex in L2 (16\%) than in L1 $(4 \%), t(7)=3.53, p=.01$. No other category differed between the languages. Therefore, as in Gullberg (2003), more instances of maintained reference were encoded in full lexical NPs in L2 than in L1. It is worth noting that the participants in this study in general used more pronouns in L2 than the learners in Gullberg (2003). This is most likely a reflection of these learners' overall higher proficiency than that of the learners in the previous study.

Turning to gestures, we examined the mean proportion of expressions of maintained reference that occurred with gestures in L1 and L2. Figure 3 summarizes the results. A paired samples $t$ test revealed that there were significantly more gestures for maintained reference in L2 (11\%) than in L1 $(2 \%), t(7)=-2.77$, $p=.03$. Again, as in Gullberg (2003), expressions of maintained

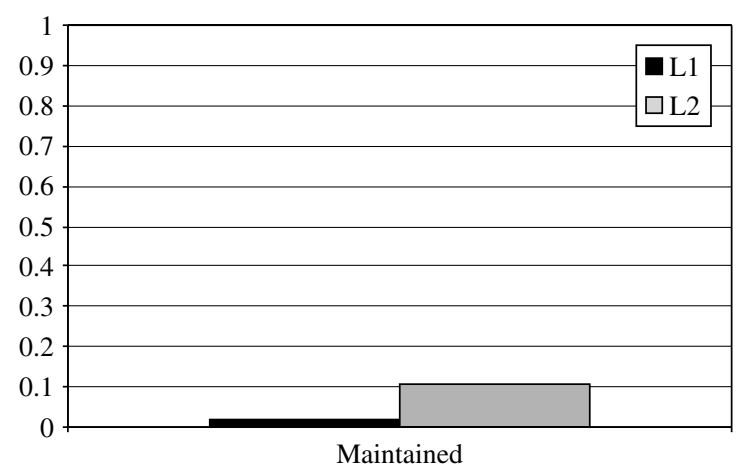

Figure 3. Mean proportion of expressions of maintained reference with gestures in L1 versus L2 (+Vis). 
reference were more likely to be marked by anaphoric gestures in L2 than in L1.

The expressions of maintained reference were further broken down by the linguistic encoding category (NP Lex, NP Pron) across the languages. Figure 4 presents the mean proportion of maintained NP Lex and NP Pron that occurred with gestures in L1 and L2. A repeated measures ANOVA with encoding category (NP Lex, NP Pron) and language (L1, L2) as within-subject factors was run on the mean scores. The results showed a main effect of encoding category, $F(1,7)=14.7$, $p=.01, \eta^{2}=.68$, and of language, $F(1,7)=5.23, p=.06$, $\eta^{2}=.43$. There was also a (marginally) significant interaction of language by encoding category, $F(1,7)=4.58, p=.07$, $\eta^{2}=.40$. Therefore, in both L1 and L2, lexical NPs were more likely to be accompanied by gestures $(23 \%, 61 \%)$ than pronouns $(0.5 \%, 3 \%)$. Also, gestures were more likely to accompany L2 reference $(63 \%, 3 \%)$ than L1 reference $(23 \%, 0.5 \%)$. Further, the interaction between encoding category and language indicates that gesturing differed for the encoding categories in L1 and L2. Paired samples $t$ tests indicated that maintained reference encoded by NP Lex was (marginally) significantly more often accompanied by gestures in L2 than in L1,



Figure 4. Mean proportion of expressions for maintained reference with gestures by encoding category (NP Lex vs. NP Pron) in L1 versus L2 (+Vis). 
$t(7)=2.23, p=.06$. No difference was found for maintained reference encoded by NP Pron.

To summarize, the findings for L1 and L2 speech and gesture under full visibility replicate the results from Gullberg (2003), confirming the characteristics of maintained reference in both modalities. In speech, maintained reference is more likely to be encoded by lexical NPs in L2 than in L1. The same category is also more likely to be accompanied by gesture in general, and even more so in L2 than in L1. Maintained reference in L2 is therefore overexplicit in both modalities.

Visibility Effects on Maintained Reference in L2 Speech and Gesture

The following analyses examine whether manipulations of visibility affect expressions of maintained reference in speech and gestures in L2. The purpose is to address the main research question, namely whether overexplicit L2 speech and gesture is an interactional communication strategy. To test the predictions summarized in Table 1, we first investigate whether overexplicit L2 speech becomes less explicit and therefore more cohesive in the -Vis condition; that is, whether it displays fewer lexical NPs and more pronouns. If it does, this would support a reading of the overexplicit nature of L2 speech as being part of an interactional communication strategy where the properties of speech depend on the copresence of disambiguating gestures. Second, we examine whether overexplicit anaphoric gestures in L2 disappear in the -Vis condition. If they do, then they are likely part of an interactional communication strategy in the + Vis condition.

The typical data patterns are illustrated in Examples (7) for L2 + Vis, and (8) for L2 -Vis.

(7) la dame ${ }^{i}$ retournE à euh [docteur] euh euh ['assistante $]^{j}$ de docteur euh [l'assistante $]^{\mathrm{j}}$ euh naar le docteur ${ }^{\mathrm{k}}$

"the lady ${ }^{\mathrm{i}}$ return to uh [doctor] uh uh [the assistant $]^{\mathrm{j}}$ of the doctor 
uh [the assistant $]^{\mathrm{j}}$ uh to the doctor ${ }^{\mathrm{k}}$,

(8) la femme ${ }^{i}$ retournE euh avec l'ordonnance à la [docteur] ${ }^{\mathrm{j}}$

le $[\text { docteur }]^{\mathrm{j}}$ comprend pas cette son papier

euh [le docteur $]^{\mathrm{j}}$ producE papier

"the woman ${ }^{\mathrm{i}}$ return uh with the prescription to the $[\text { doctor }]^{\mathrm{j}}$

the $[\text { doctor }]^{j}$ doesn't understand this his paper

uh [the doctor $]^{\mathrm{j}}$ produce paper"

Example (7) demonstrates the typical pattern for L2 maintained reference under full visibility, which we have already seen in the Replication analysis. A maintained referent, l'assistante ${ }^{j}$ "the assistant," is encoded by a full lexical NP and accompanied by an anaphoric gesture. Example (8) exemplifies L2 maintained reference under no visibility. It is strikingly similar to Example (7). Again, the immediately maintained referent, le docteur ${ }^{j}$ "the doctor ${ }^{\mathrm{j}}$," is indicated with a full lexical NP and anaphoric gestures.

Figure 5 presents the mean proportion of instances of maintained reference encoded as NP Lex, NP Pron, or NP Ø in

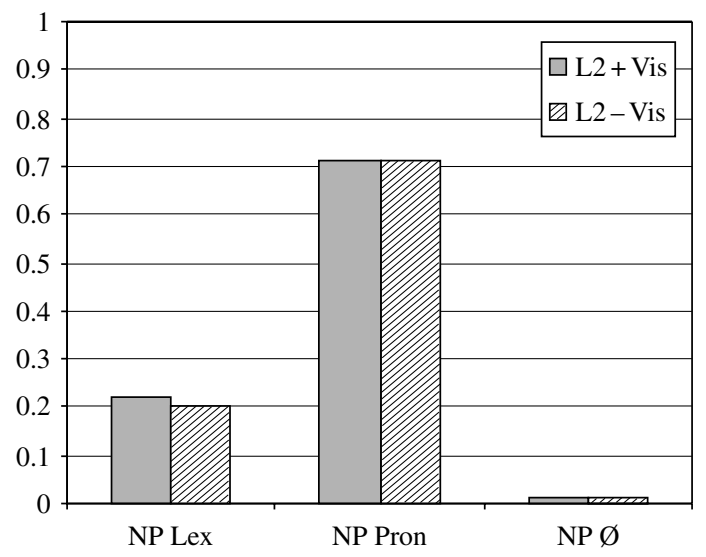

Figure 5. Mean proportion of maintained reference encoded as NP Lex, NP Pron, or NP $\varnothing$ in L2 + Vis and L2 -Vis. 
L2 + Vis and L2 -Vis. A repeated measures ANOVA for maintained reference with encoding category (NP Lex, NP Pron, NP Ø) and visibility (+Vis, -Vis) as within-subject factors was run on the mean scores. The results showed a main effect of encoding category, $F(2,9)=48.73, p \leq .00, \eta^{2}=.92$. No interaction was found between encoding category and visibility condition, $F(2,9)=1, p=1, \eta^{2}=.02$. Participants thus encoded maintained reference in speech the same way in both visibility conditions. ${ }^{5}$

Next, we examined the mean proportion of expressions for maintained reference occurring with gestures across the two visibility conditions. Figure 6 displays the results. The amount of gesturing was identical in both conditions (16\% vs. 16\%) and no significant difference in gesture performance could be found, $t(9)=-.03, p=.97 .^{6}$

Maintained reference was also broken down by encoding category (NP Lex, NP Pron), as summarized in Figure 7. A repeated measures ANOVA with encoding category (NP Lex, NP Pron) and visibility (+Vis, - Vis) was run on the mean scores. The results showed a main effect of encoding category, $F(1,9)=14.97, \quad p \leq .00, \eta^{2}=.62$, but no interaction with visibility. Gestures were thus significantly more likely to occur

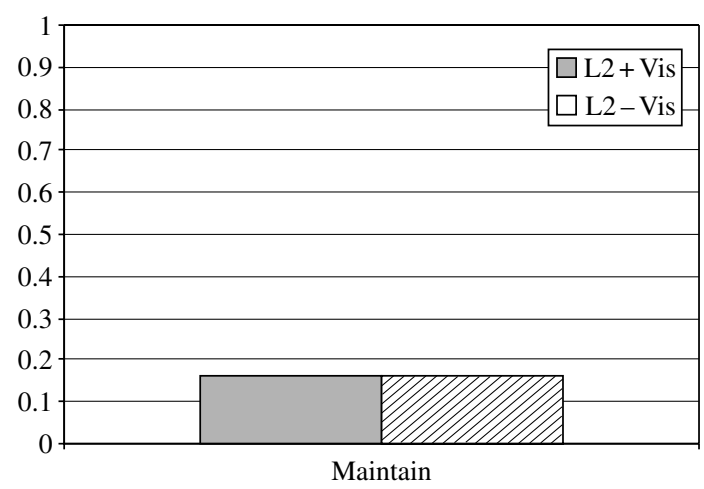

Figure 6. Mean proportion of expressions for maintained reference occurring with gestures in L2 + Vis and L2 -Vis. 
with lexical NPs $(51 \%, 63 \%)$ than with pronouns $(7 \%, 8 \%)$ in both visibility conditions.

To summarize the visibility analyses, no quantitative difference was found in speech or gesture behavior for maintained reference between the two visibility conditions in L2. In other words, speech was encoded the same way regardless of visibility condition, and the number of anaphoric gestures and their affiliation to lexical NPs remained the same even when the gestures could not be seen by the addressee.

\section{Visibility Effects: A Qualitative Consideration}

Although there was no quantitative difference between the visibility conditions, cohesive gestures for introduced, maintained, as well as reintroduced reference in L2 were qualitatively different in the visibility condition from the gestures in the nonvisibility condition. This difference is exemplified in Figures 8a and 8b. The spatial properties of anaphoric gestures appear to be sensitive to changes in visibility. Gesture space is more differentiated in the +Vis condition than in the - Vis condition. Cohesive gestures in the + Vis condition are

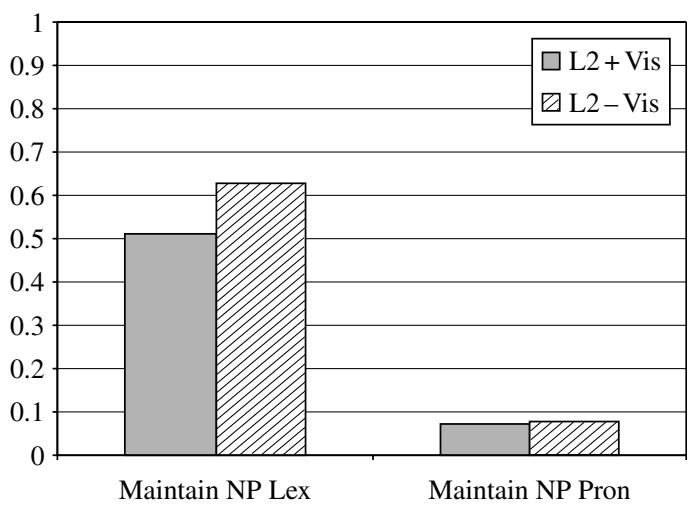

Figure 7. Mean proportion of expressions of maintained reference occurring with gestures per encoding category (NP Lex, NP Pron) across visibility conditions. 
spatially well defined and differentiated. Loci associated with particular referents are kept well apart in space. In contrast, in the -Vis condition, localizing gestures are less well defined and less spatially differentiated (the loci form almost a single cluster in Figure 8b). This is partly an artifact of the setup and the fact that the barrier constrains gestural space. However, reduced spatial differentiation is not a necessary consequence of a sagitally more constrained gesture space. Speakers can and do differentiate space in the lateral dimension. An additional observation is that the individual gestures are not necessarily larger or better articulated in the + Vis condition. Cohesive gestures are often quite small and casual even in the +Vis condition, but their directionality is often specific. The gestures in the -Vis condition are of the same size as gestures in the + Vis condition but typically have vague directionality.

A more specific difference between the conditions concerns the tendency to adhere to loci set up over discourse, a phenomenon that might be labeled locus permanence. In the $+\mathrm{Vis}$ condition, speakers often adhere to loci throughout a narrative, such that when a referent is referred back to, the locus associated with it is clearly indicated. Notice that this includes taking into account that the referent might have moved in gesture space as a result of gesturing for actions undertaken
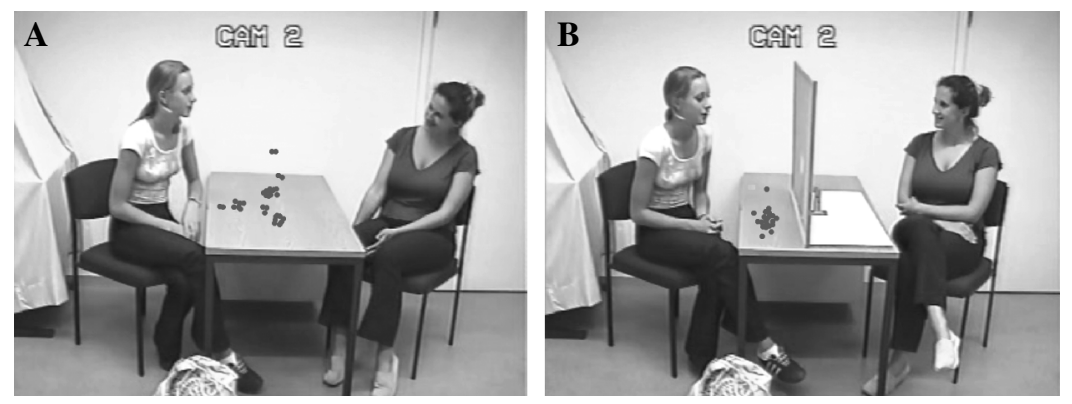

Figure 8. Spatial distribution of loci (dots) in the + Vis and -Vis conditions: (a) spatially distinct loci in the +Vis condition; (b) vague spatial loci in the -Vis condition. 
by the referent and keeping track of the new location with which it is currently associated. In the -Vis condition, in contrast, locus permanence is not as rigorously observed. Notice, again, that this is not a necessary consequence of a more constrained gesture space.

A third analysis was undertaken to investigate locus permanence quantitatively across the conditions. In each narrative, the first gesture/locus associated with a particular referent was identified. All subsequent gestures coinciding with a spoken referential expression referring to that same referent (i.e., maintained as well as reintroduced), labeled second occurrence gestures, were coded for locus permanence. They were coded as either (a) spatially permanent (clearly referring back to a location previously set up) or (b) vague. Locus permanence was thus coded referent by referent. The analysis is based on data from all participants who provided second occurrence gesture data (i.e., maintained and reintroduced reference) in both L2 visibility conditions. Interrater reliability on the entire data set was $.95(N=177)$. Figures $9 \mathrm{a}$ and $9 \mathrm{~b}$ illustrate two gestures associated with the same referent and the locus permanence as estimated by visual inspection and by pixel coordinates.
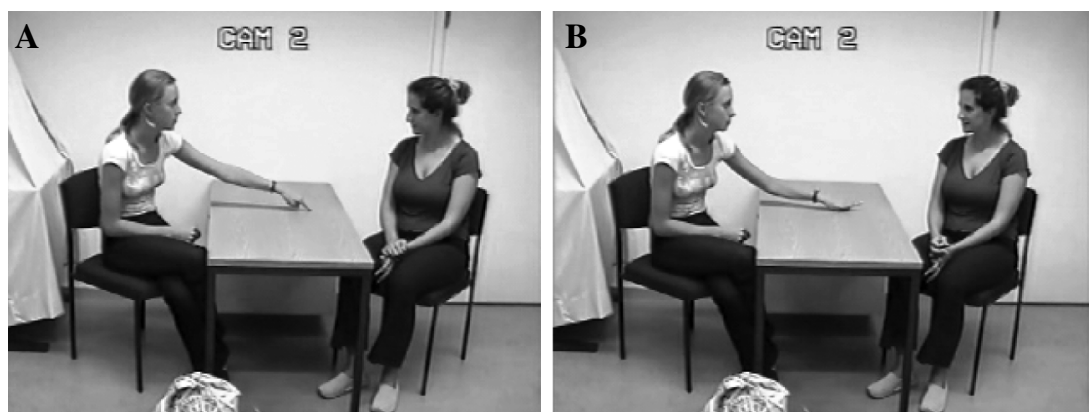

Figure 9. (a) The reintroduction of a referent (refstatus R) and the associated gesture (\#21); gesture space maintained from the previous mention (LP). Pixel coordinates given. (b) Maintenance of the same referent $6 \mathrm{~s}$ later (refstatus M) and the associated gesture (\#23); gesture space maintained (LP). Pixel coordinates also given. 
The mean proportion of gestures in each visibility condition coded as spatially permanent versus vague were computed. Figure 10 presents the results. A repeated measures ANOVA with locus permanence (Permanent, Vague) and visibility (+Vis, -Vis) as within-subject factors was run on the mean scores. The results showed a main effect of locus permanence, $F(1,11)=8.97, p=.01, \eta^{2}=.45$, and an interaction of locus permanence by visibility, $F(1,11)=4.768, p=.052, \eta^{2}=.30$, suggesting that the degree of locus permanence observed differed across the visibility conditions. Paired samples $t$ tests showed that there were significantly more spatially permanent gestures in the $+\mathrm{Vis}(42 \%)$ than the $-\mathrm{Vis}(16 \%)$ condition, $t(11)=2.18, p=.05$, and significantly more spatially vague gestures in the $-\mathrm{Vis}(84 \%)$ than the $+\mathrm{Vis}(58 \%)$ condition, $t(11)=-2.19, \quad p=.05$. Also, vague gestures significantly outnumbered spatially permanent gestures in the -Vis condition ( $84 \%$ vs. $16 \%), t(11)=-5.41, p \leq .00$.

Speech accompanying spatially permanent and spatially vague gestures was also examined to determine whether locus permanence in gesture had any bearing on speech. Simple lexical NPs (9), heavier, adjectivally modified NPs (10), and

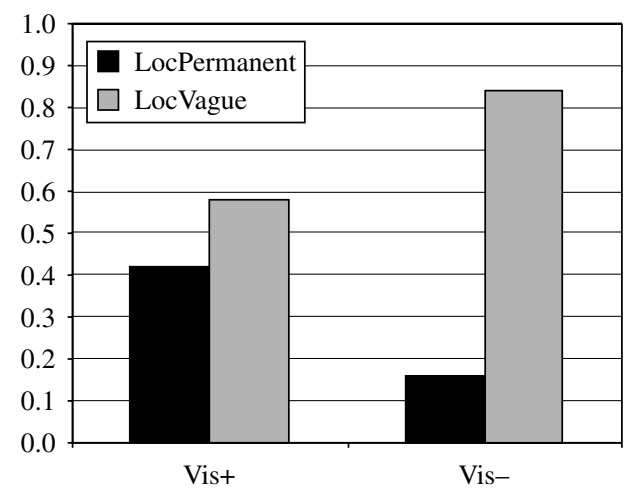

Figure 10. Mean proportion of gestures across visibility conditions coded as Locus Permanent versus Locus Vague. 
prepositionally modified NPs (11) occurred with both types of gestures.

\section{Spatially permanent}

La femme, le monsieur, l'assistant

"the woman, the mister, the assistant”

(10) Le premier garçon, l'autre femme "the first boy, the other woman"

(11) La assistante de pharmacie

"the assistant of the pharmacy"
Spatially vague

Le femme, le monsieur, le secretaire

"the woman, the mister, the secretary"

Le premier monsieur, un autre femme "the first mister, another woman"

L'autre femme de magasin

"the other woman of the shop"

The mean proportions of these encoding categories appearing with each gesture type were computed and a repeated measures ANOVA with locus permanence (Permanent, Vague) and encoding category (Simple NP, Adjectival NP, Prepositional NP) as within-subject factors was run on the mean scores. The results showed a main effect of encoding category, $F(2,11)=164.44, p \leq .00, \eta^{2}=.97$, but no interaction of locus permanence by encoding category, $F(2,11)=3, \quad p=.10$, $\eta^{2}=.38$, suggesting that the degree of locus permanence in gestures did not affect the nominal expressions in speech.

In sum, the quantitative analysis of the qualitative difference in the gestural cohesion patterns across the visibility conditions revealed that learners adhere more closely to the loci set up in association with a referent when these loci can be seen by the addressee than when they cannot. The actual articulation of the cohesive gestures is thus influenced by the interactive situation.

\section{Discussion}

This study investigated whether L2 speakers' bimodally overexplicit expressions for maintained reference (i.e., anaphoric gestures performed in conjunction with overexplicit nominal reference in speech) are part of an interactionally intended 
communication strategy. The test paradigm manipulated addressees' visible access to the learners' gestures. The logic behind this paradigm is that if gestures accompanying expressions of maintained reference disappear when they are not visible to the addressee, then these gestures are part of an addressee-directed, interactional communication strategy for disambiguation. Similarly, if speech changes when gestures are not visible, then overexplicitness in speech might be part of a communication strategy.

There are four main findings. First, this study replicated results regarding the properties of overexplicit maintained reference in L2 speech and gesture in the production of Dutch learners of L2 French. In early L2 speech, maintained reference is more often expressed with lexical NPs than in L1. These same lexical NPs are also overmarked by anaphoric gestures in L2. Notice that the pattern of bimodal cohesion might be subject to typological variation (see Hendriks, 2003; Yoshioka, 2005), depending on the encoding categories and preferred discourse patterns of the languages involved. However, for the Western European languages studied so far (Swedish, French, and Dutch), the pattern is replicated.

Second, the manipulation of visibility did not affect L2 speech. Maintained reference was encoded by lexical NPs in both visibility conditions. The overexplicit spoken learner variety of cohesion is therefore not motivated by the presence of anaphoric and potentially disambiguating gestures. Instead, and as expected, it reflects an acquisitional stage in which pronouns and zero anaphora have not been acquired in the L2 or, alternatively, a stage where the processing load of planning at both a local level and a global level is too heavy for learners. Therefore, there is little support for the idea that overexplicit maintained reference in L2 speech is strategically dependent on the presence of disambiguating gestures.

Third, the presence of overexplicit cohesive gestures in L2 does not depend on the visible access of the addressee to those gestures. Rather surprisingly, there was no quantitative 
difference in anaphoric gesturing between the visibility conditions. Anaphoric gestures remained present even when not visible to the addressee. This finding suggests that learners do not mainly produce these gestures for the benefit of the addressee and that their existence is, therefore, not interactionally or strategically motivated.

Fourth, although the presence of anaphoric gestures does not depend on whether they are visible to the addressee, their form and articulation do. When gestures are visible to the addressee, learners perform them with greater spatial distinction and differentiation. They maintain the spatial setup of loci significantly more often when the gestures can be seen by the addressee than when they cannot. This finding suggests that learners draw on anaphoric gestures for interactional and possibly strategic purposes if they are available as a resource.

The findings rule out that the characteristics of overexplicit maintained reference in speech are part of an interactional communication strategy. This was to be expected. Learners at this proficiency level do not have the linguistic means in this domain to alter their speech strategically. The results do not, however, rule out the possibility that the gestural cohesive pattern is part of an interactional communication strategy. The qualitative effects on the articulation and realization of cohesive gestures when they can be seen point to interactional and communicative intent. Speakers (and learners) do take their addressee into account when performing such gestures. The spatial information that these gestures provide is put to good use. Their careful spatial realization and the observance of locus permanence in L2 (and L1) indicate a certain "recipient design" (Sacks \& Schegloff, 1979). Whether this is because learners make inferences about the native listeners' interpretation difficulties and need for disambiguation or whether it is a direct result of visibility is an open question. Either way, the qualitative properties of cohesive gestures make it probable that learners exploit them as a communication strategy wherever feasible and practical. Although learners have no choice but to flout rules for anaphora 
resolution and to be overexplicit in speech, they do what they can to overcome the resulting ambiguity and they exploit anaphoric gestures for disambiguation wherever possible.

The question still remains of why the overexplicit cohesive gestures remain when they cannot be seen. Although other studies of visibility manipulations have not dealt with cohesive gestures, the result is still compatible with previous findings. Alibali et al. (2001) speculated that visibility manipulations would only affect gestures that add information relative to speech. Because the presence of anaphoric gestures is not affected by changes in visibility, this suggests that they do not provide additional but rather redundant information with regard to speech. Indeed, in terms of linguistic information, they do not provide any additional information about a referent besides its presence. Therefore, they do not appear to be good candidates for interactional communication strategies of disambiguation. It has been suggested that they are a mere reflection of habitual movement patterns, that speakers continue to gesture out of habit regardless of the situation (see, e.g., Hostetter \& Hopkins, 2002). However, the fact that L2 gestures differ from L1 gestures and that there is a qualitative change in realization depending on visibility speaks against such an option. Another possibility is that the presence of cohesive gestures reflects processes related to speech production, planning, and cognitive load. As such, anaphoric gestures might in fact be part of learners' means to help themselves.

In the field of gesture studies, observers agree that all gestures are not interactionally motivated. For instance, speakers gesture on the phone, and congenitally blind speakers gesture even though they cannot see their interlocutors (e.g., Iverson, Tencer, Lany, \& Goldin-Meadow, 2000). Several theories have recently been developed that assign a role to gesture in speech production processes. One set of theories proposes that gestures facilitate speech by helping lexical retrieval (e.g., Frick-Horbury \& Guttentag, 1998; Hostetter \& Hopkins, 2002; Krauss, 1998; Krauss, Chen, \& Gottesman, 
2000; Rauscher, Krauss, \& Chen, 1996) or by promoting the organization of thought for verbalization (e.g., Alibali, Kita, \& Young, 2000; Freedman, 1972; Kita, 2000). Another set of theories considers gesture and speech as equal partners with a shared conceptual origin that is expressed linearly in speech and holistically in gesture simultaneously (e.g., De Ruiter, 2000; McNeill, 1992). At first glance, the speech facilitation theories seem applicable to L2 production and reference tracking in L2, given their view of gestures as compensatory. However, these theories have a number of problems. First, they rest on the assumption that gestures precede speech such that gesturing for retrieval occurs in silence. This assumption has little support in empirical data. Careful analyses reveal that when speech stops, so does gesture, be it in stuttering (Mayberry \& Jaques, 2000), in disfluency (Seyfeddinipur, 2005; Seyfeddinipur \& Kita, 2001), or in L2 production (Gullberg, 1998). Very little gesturing and certainly no cohesive gesturing occur in pauses or in silence. Moreover, these theories largely refer to retrieval of content words and to representational/lexical/iconic gestures (i.e., gestures that represent some feature of the intended referent). In the case of reference tracking, there is no lack of lexical material; rather, the opposite is true. Also, the localizing gestures pertinent here are often abstract deictic gestures that bear no iconic relationship to the referent. It therefore seems difficult to account for L2 cohesive gestures as a reflection of lexical retrieval processes or, indeed, of organization of thought for verbalization. In fact, in the case of L2, a lexical retrieval account is unlikely even for representational gestures, given that the lexeme in L2 that corresponds to the assumed intended L1 concept is not always known by the learner. Therefore, no amount of gesturing will activate the sought lexical item. Neither of these compensatory views on gesture seems to be able to account for gestural cohesion patterns in L1 or in L2.

An alternative but still facilitative view has recently been suggested. It proposes that gestures reduce load on verbal working memory by virtue of shifting some of the load onto 
other cognitive systems or to external representations. In a series of studies Goldin-Meadow and her colleagues (GoldinMeadow, Nusbaum, Kelly, \& Wagner, 2001; Wagner, Nusbaum, \& Goldin-Meadow, 2004) have measured recall on memory tasks in children and adults who had to explain a math problem between memorizing lists and being tested for recall. Some participants gestured while explaining the math problem and others did not. Participants who gestured during the math explanation performed significantly better on the memory tasks than those who did not gesture. This is interpreted as suggesting that gesturing frees up cognitive resources that can be allocated to other tasks, such as keeping words in short-term memory. Following this line of argument, anaphoric gestures for maintained and reintroduced reference in L2 could be "compensatory," conferring a cognitive benefit to the learner, in the sense that they alleviate learners' cognitive load, allowing them to proceed to plan the next unit of discourse.

This account seems compatible with the general observation that early L2 speech is nonfluent and proceeds by small units, many of which are typically accompanied by gestures (Gullberg, 1998; Nobe, 1993). The learner in (12) produces a gesture on almost every unit or argument of the utterance: one gesture with the predicate, ger "gives," another with the referential expression in direct object position, papper "paper," as well as one with the oblique object, till apotekarin "to the pharmacist."

(12) hon eh [ger] hon ger eh [pa papper] papper eh [till apotekarin]

"she uh [gives] she gives uh [pa paper] paper uh [to the pharmacist]"

If gestures do free up cognitive resources, a gesture on a maintained referent expressed as a lexical NP could be taken to mean that this entity has been planned and executed as a separate unit, much as if it were a new idea, not related to the preceding context. Moreover, this view is in line with the processing explanations for overexplicit speech by which 
learners use lexical NPs to avoid a double planning load (Carroll \& Lambert, 2003; Carroll et al., 2000; Prodeau, 1998). Keeping words, grammar, and relationships between entities at a local level and global level in mind simultaneously is a very heavy load on verbal working memory and thus for speech planning. If lexical NPs help you reduce the planning load, performing a gesture as you go along might help alleviate the load even further. In this sense, anaphoric gestures in L2 might be regarded as cognitive or psycholinguistic communication strategies. If, in addition, they help learners to produce continued output (cf. Swain, 2000), then they might have interactional value as well, and possibly even acquisitional value in that they promote the opportunity for L2 language use in context. In sum, anaphoric gestures could be multifunctional in that they do interactional (strategic) work for addressees whenever possible and possibly also cognitive work for the learners themselves. This line of reasoning opens up a range of new theoretical and empirical questions to be explored both in the field of gesture studies and in second language acquisition research.

Revised version accepted 8 September 2005

\section{Notes}

${ }^{1}$ Information organizational principles might underlyingly be the same crosslinguistically but they map onto a specific language differentially, possibly due to the specifics of the grammar of that language (Carroll \& Lambert, 2003; Carroll et al., 2000; Lambert, Carroll, \& Stutterheim, 2003; Watorek, 2003; Yoshioka, 2005). The reorganization of these principles remains a problem even at very advanced levels of acquisition. However, at the proficiency level relevant here, transfer of the L1 principles is to be expected.

${ }^{2}$ As pointed out by a reviewer, an experimental design that manipulates visual access will not definitively determine what is interactional from what is speaker-internal. However, such a design might contribute to qualifying claims about what aspects of gesture behavior are chiefly motivated by interactional concerns for the addressee from those aspects that seem to serve a more speaker-internal function.

${ }^{3}$ Notice that this procedure excludes gestures co-occurring with predications or verbs. Gestures occurring with the verb, as in (i), were therefore excluded. 
(i) The woman [went] to the doctor.

Gestures occurring with predicates generally do not mark referents, only actions and events, and are, therefore, not pertinent here. However, insofar as such action-related gestures "moved" the referent from one location to another, the spatial reorganization was noted.

${ }^{4}$ The alpha level is .05 throughout this paper. For effect size, $\eta^{2}$ is reported, and the guidelines proposed by Cohen (1988) are followed: .01 = small, $.06=$ moderate, $.14=$ large.

${ }^{5} \mathrm{~A}$ reviewer suggested that $\mathrm{L} 1$ speech might also be affected by changes in visibility, but in the opposite direction, such that -Vis might lead to a greater degree of explicitness and the use of more lexical NPs for maintained reference. A parallel analysis was therefore undertaken comparing speech in L1 production under the two visibility conditions. The results show a main effect of encoding category, $F(2,13)=469.333$, $p \leq .000, \eta^{2}=.99$, but no interaction with visibility, $F(2,13)=2.436$, $p=.126, \eta^{2}=.27$. The results are the same as for the L2 analysis: maintained reference was encoded the same way in L1 speech in both visibility conditions, and no tendency toward an increased use of full lexical NPs could be found in the -Vis condition. This is less surprising than it might first seem. Studies showing (visibility) effects on the degree of explicitness in speech typically investigate spatial language or reference to complex entities (tangram pictures) rather than reference to person in narratives (e.g., Bard, et al., 2000; Clark \& Haviland, 1977; Clark \& Wilkes-Gibbs, 1986). Longer and more elaborate expressions in speech might be necessary when talking about such complex spatial entities than when referring to already introduced protagonists in narratives.

\section{References}

Alibali, M. W., Heath, D. C., \& Myers, H. J. (2001). Effects of visibility between speaker and listener on gesture production: Some gestures are meant to be seen. Journal of Memory and Language, 44, 169-188.

Alibali, M. W., Kita, S., \& Young, A. J. (2000). Gesture and the process of speech production: We think, therefore we gesture. Language and Cognitive Processes, 15, 593-613.

Ariel, M. (1990). Accessing noun phrase antecedents. New York: Routledge. Bard, E. G., Anderson, A. H., Sotillo, C., Aylett, M., Doherty-Sneddon, G., \& Newlands, A. (2000). Controlling the intelligibility of referring expressions in dialogue. Journal of Memory and Language, 42, 1-22.

Bavelas, J. B., Chovil, N., Lawrie, D. A., \& Wade, A. (1992). Interactive gestures. Discourse Processes, 15, 469-489. 
Beattie, G., \& Shovelton, H. (1999). Do iconic hand gestures really contribute anything to the semantic information conveyed by speech? Semiotica, 123, 1-30.

Berger, K. W., \& Popelka, G. R. (1971). Extra-facial gestures in relation to speech reading. Journal of Communication Disorders, 3, 302-308.

Bialystok, E. (1990). Communication strategies: A psychological analysis of second-language use. Oxford: Blackwell.

Bialystok, E. (1994). Analysis and control in the development of second language proficiency. Studies in Second Language Acquisition, $16,157-168$.

Brugman, H., \& Kita, S. (1995). Impact of digital video technology on transcription: A case of spontaneous gesture transcription. KODIKAS / CODE: Ars Semeiotica, 18, 95-112.

Carroll, M., \& Lambert, M. (2003). Information structure in narratives and the role of grammaticised knowledge. A study of adult French and German learners of English. In C. Dimroth \& M. Starren (Eds.), Information structure and the dynamics of language acquisition (pp. 267-287). Amsterdam: Benjamins.

Carroll, M., Murcia-Serra, J., Watorek, M., \& Bendiscoli, A. (2000). The relevance of information organization to second language acquisition studies: The descriptive discourse of advanced adult learners of German. Studies in Second Language Acquisition, 22, 441-466.

Cassell, J., McNeill, D., \& McCullough, K.-E. (1999). Speech-gesture mismatches: Evidence for one underlying representation of linguistic and nonlinguistic information. Pragmatics \& Cognition, 7, 1-33.

Chafe, W. (1994). Discourse, consciousness, and time. Chicago: University of Chicago Press.

Church, R. B., \& Goldin-Meadow, S. (1986). The mismatch between gesture and speech as an index of transitional knowledge. Cognition, 23, 43-71.

Clark, H. H. (1996). Using language. Cambridge: Cambridge University Press.

Clark, H. H., \& Haviland, S. E. (1977). Comprehension and the Given-New contract. In R. O. Freedle (Ed.), Discourse production and comprehension (Vol. 1, pp. 1-40). Norwood, NJ: Ablex.

Clark, H. H., \& Wilkes-Gibbs, D. (1986). Referring as a collaborative process. Cognition, 22, 1-39.

Cloitre, M., \& Bever, T. G. (1988). Linguistic anaphors, levels of representation and discourse. Language and Cognitive Processes, 3, 293-322.

Cohen, A. (1977). The communicative function of hand gestures. Journal of Communication, 27, 54-63. 
Cohen, A., \& Harrison, R. P. (1973). Intentionality in the use of hand illustrators in face-to-face situations. Journal of Personality and Social Psychology, 6, 341-349.

Cohen, J. (1988). Statistical power analysis for the behavioral sciences. Hillsdale, NJ: Erlbaum.

De Ruiter, J.-P. (2000). The production of gesture and speech. In D. McNeill (Ed.), Language and gesture: Window into thought and action (pp. 284311). Cambridge: Cambridge University Press.

Dörnyei, Z., \& Scott, M. L. (1997). Communication strategies in a second language: Definitions and taxonomies. Language Learning, 47, 173-210.

Duncan, S. (1994). Grammatical form and "thinking-for-speaking" in Mandarin Chinese and English: An analysis based on speech-accompanying gesture. Unpublished doctoral dissertation, University of Chicago, Chicago.

Engberg-Pedersen, E. (1993). Space in Danish sign language. Hamburg: Signum.

Extra, G., Strömqvist, S., \& Broeder, P. (1988). Pronominal reference to persons in adult second language acquisition. In P. Broeder, G. Extra, R. v. Hout, S. Strömqvist, \& K. Voionmaa (Eds.), Processes in the developing lexicon (Vol. 3, pp. 86-113). Strasbourg: European Science Foundation.

Faerch, C., \& Kasper, G. (1983a). On identifying communication strategies in interlanguage production. In C. Faerch \& G. Kasper (Eds.), Strategies in interlanguage communication (pp. 210-238). London: Longman.

Faerch, C., \& Kasper, G. (1983b). Plans and strategies in foreign language communication. In C. Faerch \& G. Kasper (Eds.), Strategies in interlanguage communication (pp. 20-60). London: Longman.

Faerch, C., \& Kasper, G. (1984). Two ways of defining communication strategies. Language Learning, 34, 45-63.

Fox, B. (1987). Discourse structure and anaphora. Cambridge: Cambridge University Press.

Freedman, N. (1972). The analysis of movement behavior during the clinical interview. In A. W. Siegman \& B. Pope (Eds.), Studies in dyadic communication (pp. 153-175). New York: Pergamon.

Frick-Horbury, D., \& Guttentag, R. E. (1998). The effects of restricting hand gesture production on lexical retrieval and free recall. American Journal of Psychology, 111, 43-62.

Garrod, S. (2001). Anaphora resolution. In N. J. Smelser \& P. B. Baltes (Eds.), International encyclopedia of the social and behavioral sciences (pp. 490-494). Amsterdam: Elsevier.

Garrod, S., Freudenthal, D., \& Boyle, E. (1994). The role of different types of anaphor in the on-line resolution of sentences in a discourse. Journal of Memory and Language, 33, 39-68. 
Givón, T. (1984). Universals of discourse structure and second language acquisition. In W. E. Rutherford (Ed.), Language universals and second language acquisition (pp. 109-136). Amsterdam: Benjamins.

Goldin-Meadow, S., Nusbaum, H., Kelly, S. D., \& Wagner, S. (2001). Explaining math: Gesturing lightens the load. Psychological Science, $12,516-522$.

Graham, J. A., \& Argyle, M. (1975). A cross-cultural study of the communication of extra-verbal meaning by gestures. International Journal of Psychology, 10, 56-67.

Grice, H. P. (1975). Logic and conversation. In P. Cole \& J. L. Morgan (Eds.), Syntax and semantics: Speech acts (Vol. 3, pp. 41-58). New York: Academic Press.

Gullberg, M. (1998). Gesture as a communication strategy in second language discourse: A study of learners of French and Swedish. Lund: Lund University Press.

Gullberg, M. (1999). Communication strategies, gestures, and grammar. Acquisition et Interaction en Langue Etrangère, Numéro spéciale: Eurosla 8. A selection of papers (ed. C. Perdue \& M. Lambert), 61-71.

Gullberg, M. (2003). Gestures, referents, and anaphoric linkage in learner varieties. In C. Dimroth \& M. Starren (Eds.), Information structure, linguistic structure and the dynamics of language acquisition (pp. 311-328). Amsterdam: Benjamins.

Hendriks, H. (2003). Using nouns for reference maintenance: A seeming contradiction in L2 discourse. In A. G. Ramat (Ed.), Typology and second language acquisition (pp. 291-326). Berlin: Mouton.

Holler, J., \& Beattie, G. (2003). Pragmatic aspects of representational gestures. Do speakers use them to clarify verbal ambiguity for the listener? Gesture, 3, 127-154.

Hostetter, A. B., \& Hopkins, W. D. (2002). The effect of thought structure on the production of lexical movements. Brain and Language, 82, 22-29.

Iverson, J. M., Tencer, H. L., Lany, J., \& Goldin-Meadow, S. (2000). The relation between gesture and speech in congenitally blind and sighted language-learners. Journal of Nonverbal Behavior, 24, 105-130.

Kasper, G., \& Kellerman, E. (Eds.). (1997). Communication strategies: Psycholinguistic and sociolinguistic perspectives. London: Longman.

Kellerman, E., \& Bialystok, E. (1997). On psychological plausibility in the study of communication strategies. In G. Kasper \& E. Kellerman (Eds.), Communication strategies: Psycholinguistic and sociolinguistic perspectives (pp. 31-48). London: Longman. 
Kelly, S. D., Barr, D. J., Breckinridge Church, R., \& Lynch, K. (1999). Offering a hand to pragmatic understanding: The role of speech and gesture in comprehension and memory. Journal of Memory and Language, 40, 577-592.

Kendon, A. (1972). Some relationships between body motion and speech: An analysis of an example. In A. W. Siegman \& B. Pope (Eds.), Studies in dyadic communication (pp. 177-210). New York: Pergamon.

Kendon, A. (1986). Some reasons for studying gesture. Semiotica, 62, 3-28.

Kendon, A. (2004). Gesture: Visible action as utterance. Cambridge: Cambridge University Press.

Kendon, A., \& Versante, L. (2003). Pointing by hand in "Neapolitan." In S. Kita (Ed.), Pointing: Where language, culture, and cognition meet (pp. 109-169). Mahwah, NJ: Erlbaum.

Kita, S. (2000). How representational gestures help speaking. In D. McNeill (Ed.), Language and gesture (pp. 162-185). Cambridge: Cambridge University Press.

Kita, S., \& Özyürek, A. (2003). What does cross-linguistic variation in semantic coordination of speech and gesture reveal? Evidence for an interface representation of spatial thinking and speaking. Journal of Memory and Language, 48, 16-32.

Kita, S., van Gijn, I., \& van der Hulst, H. (1998). Movement phases in signs and co-speech gestures, and their transcription by human coders. In I. Wachsmuth \& M. Fröhlich (Eds.), Gesture and sign language in human-computer interaction (pp. 23-35). Berlin: SpringerVerlag.

Klein, W., \& Perdue, C. (1997). The basic variety (or: Couldn't natural languages be much simpler?). Second Language Research, 13, 301-347.

Krauss, R. K., Chen, Y., \& Gottesman, R. F. (2000). Lexical gestures and lexical access: A process model. In D. McNeill (Ed.), Language and gesture (pp. 261-283). Cambridge: Cambridge University Press.

Krauss, R. M. (1998). Why do we gesture when we speak? Current Directions in Psychological Science, 7, 54-59.

Lambert, M., Carroll, M., \& Stutterheim, C. v. (2003). La subordination dans les récits d'apprenants avancés francophones et germanophones de l'anglais. Acquisition et Interaction en Langue Étrangère, 19, 41-69.

Langton, S. R. H., O’Malley, C., \& Bruce, V. (1996). Actions speak no louder than words: Symmetrical cross-modal interference effects in the processing of verbal and gestural information. Journal of Experimental Psychology: Human Perception and Performance, 22, 1357-1375.

Levinson, S. C. (2000). Presumptive meanings: The theory of generalized conversational implicature. Cambridge, MA: MIT Press. 
Levy, E. T., \& Fowler, C. A. (2000). The role of gestures and other graded language forms in the grounding of reference in perception. In D. McNeill (Ed.), Language and gesture (pp. 215-234). Cambridge: Cambridge University Press.

Levy, E. T., \& McNeill, D. (1992). Speech, gesture, and discourse. Discourse Processes, 15, 277-301.

Liddell, S. K. (2003). Grammar, gesture, and meaning in American Sign Language. Cambridge: Cambridge University Press.

Marslen-Wilson, W. D., Levy, E., \& Komisarjevsky Tyler, L. (1982). Producing interpretable discourse: The establishment and maintenance of reference. In R. J. Jarvella \& W. Klein (Eds.), Language, place, and action: Studies in deixis and related topics (pp. 339-378). Chichester: John Wiley.

Mayberry, R. I., \& Jaques, J. (2000). Gesture production during stuttered speech: Insights into the nature of gesture-speech integration. In D. McNeill (Ed.), Language and gesture (pp. 199-214). Cambridge: Cambridge University Press.

McNeill, D. (1992). Hand and mind: What the hands reveal about thought. Chicago: Chicago University Press.

McNeill, D. (2000). Catchments and contexts: Nonmodular factors in speech and gesture production. In D. McNeill (Ed.), Language and gesture (pp. 312-238). Cambridge: Cambridge University Press.

McNeill, D., \& Levy, E. T. (1993). Cohesion and gesture. Discourse Processes, 16, 363-386.

Melinger, A., \& Levelt, W. J. M. (2004). Gesture and the communicative intention of the speaker. Gesture, 4, 119-141.

Nobe, S. (1993). Cognitive processes of speaking and gesturing: $A$ comparison between first language speakers and foreign language speakers. Unpublished master dissertation, University of Chicago, Chicago.

Perdue, C. (1996). Pre-basic varieties: The first stages of second language acquisition. Toegepaste taalwetenschap in artikelen. Special Issue. EUROSLA 6. A selection of papers (ed. E. Kellerman, B. Weltens \& T. Bongaerts), 135-149.

Poulisse, N. (1990). The use of compensatory strategies by Dutch learners of English. Dordrecht: Foris.

Poulisse, N. (1994). Communication strategies in a second language, The Encyclopedia of language and linguistics (Vol. 2, pp. 620-624). Oxford: Pergamon Press. 
Prodeau, M. (1998). La syntaxe dans le discours instructionnel en LE: Maintien de la référence dans le domaine des entités. Acquisition et Interaction en Langue Étrangère, 11, 95-141.

Rauscher, F. H., Krauss, R. M., \& Chen, Y. (1996). Gesture, speech and lexical access: The role of lexical movements in speech production. Psychological Science, 7, 226-231.

Riseborough, M. G. (1981). Physiographic gestures as decoding facilitators: Three experiments exploring a neglected facet of communication. Journal of Nonverbal Behavior, 5, 172-183.

Sacks, H., \& Schegloff, E. A. (1979). Two preferences in the organization of reference to persons in conversation and their interaction. In G. Psathas (Ed.), Everyday language: Studies in ethnomethodology (pp. 15-21). New York: Irvington.

Seyfeddinipur, M. (2005). Disfluency: Evidence from speech and gesture. Unpublished doctoral dissertation, Radboud University, Nijmegen.

Seyfeddinipur, M., \& Kita, S. (2001). Gesture and dysfluencies in speech. In C. Cavé, I. Guaïtella \& S. Santi (Eds.), Oralité et gestualité (pp. 266-270). Paris: L'Harmattan.

Sperber, D., \& Wilson, D. (1986). Relevance: Communication and cognition. Oxford: Blackwell.

Swain, M. (2000). The output hypothesis and beyond: Mediating acquisition through collaborative dialogue. In J. P. Lantolf (Ed.), Sociocultural theory and second language learning (pp. 97-114). Oxford: Oxford University Press.

Tarone, E. (1980). Communicative strategies, foreigner talk and repairs in interlanguage. Language Learning, 30, 417-431.

Vonk, W., Hustinx, L. G. M. M., \& Simons, W. H. G. (1992). The use of referential expressions in structuring discourse. Language and Cognitive Processes, 7, 301-333.

Wagner, S. M., Nusbaum, H., \& Goldin-Meadow, S. (2004). Probing the mental representation of gesture: Is handwaving spatial? Journal of Memory and Language, 50, 395-407.

Watorek, M. (2003). The development of anaphoric means to refer to space and entities in the acquisition of French by Polish learners. In C. Dimroth \& M. Starren (Eds.), Information structure, linguistic structure and the dynamics of language acquisition (pp. 329-355). Amsterdam: Benjamins.

Williams, J. (1988). Zero anaphora in second language acquisition. Studies in Second Language Acquisition, 10, 339-370.

Yoshioka, K. (2005). Linguistic and gestural introduction and tracking of referents in L1 and L2 discourse. Unpublished doctoral dissertation, Radboud University, Nijmegen. 
Yule, G., \& Tarone, E. (1997). Investigating communication strategies in L2 reference: Pros and cons. In G. Kasper \& E. Kellerman (Eds.), Communication strategies: Psycholinguistic and sociolinguistic perspectives (pp. 17-30). London: Longman.

Zipf, G. K. (1949). Human behavior and the principle of least effort: An introduction to human ecology. New York: Hafner. 